\title{
To Compare the Efficacy of Dexamethasone versus Normal Saline when Added As Adjuvant to 0.5\% Ropivacaine in Supraclavicular Brachial Plexus Block for Upper Extremity Surgeries
}

\author{
Bhavini Shah, ${ }^{1}$ Jateen Amonkar, ${ }^{2}$ Tripti Nagdev, ${ }^{3}$ Arnab Paul, ${ }^{4}$ Aparajita \\ Nathroy, ${ }^{5}$ Harshi Shah, \\ ${ }^{I}$ (Associate Professor, Dept of Anaesthesia, Dr. D. Y. Patil Medical College, Dr. D. Y. Patil Vidyapeeth \\ [DPU], Pune) \\ 2, 3, 5, 6(Junior Resident, Dept of Anaesthesia, Dr. D. Y. Patil Medical College, Dr. D. Y. Patil Vidyapeeth \\ [DPU], Pune) \\ ${ }^{4}$ (Senior Resident, Dept of Anaesthesia, Dr. D. Y. Patil Medical College, Dr. D. Y. Patil Vidyapeeth \\ [DPU], Pune)
}

\begin{abstract}
:
Introduction: Brachial plexus block is a reliable regional anaesthetic technique and a suitable alternative to general anaesthesia for upper limb surgery. We used dexamethasone $8 \mathrm{mg}$ along with $0.5 \%$ ropivacaine for supraclavicular brachial plexus block.

Aims: We aimed at assessing the effect of dexamethasone as an adjuvant with ropivacaine in supraclavicular brachial plexus block.

Methods and materials: Sixty ASA grade I and II patients, 18-60 years old, scheduled for upper limb surgeries under supraclavicular brachial plexus block, were included in this prospective study. The patients were randomly assigned to two groups, Group $R S$ which received ropivacaine $0.5 \% 28 \mathrm{ml}+2 \mathrm{ml}$ normal saline and Group RD which received ropivacaine 0.5\% $28 \mathrm{ml}+2 \mathrm{ml}$ dexamethasone $(8 \mathrm{mg})$. Onset and recovery time of sensory and motor block, duration of analgesia and quality of block were studied in both groups.

Results: The two groups were comparable in demographic data. Group RD showed early onset of sensory and motor block $(P<0.05)$. Duration of sensory and motor block was also prolonged in group $R D .(P<0.05)$ Conclusion: Addition of dexamethasone 8mg to 0.5\% ropivacaine for supraclavicular brachial plexus block provides faster onset and prolonged duration of sensory and motor blockade.
\end{abstract}

Keywords: Dexamethasone, Ropivacaine, supraclavicular brachial plexus block

\section{Introduction}

Brachial plexus block is a reliable regional anaesthetic technique and a suitable alternative to general anaesthesia for upper limb surgery. The supraclavicular approach provides the most complete and reliable anaesthesia as it provides anaesthesia of the entire distal upper extremity in the most consistent, time efficient manner of the many brachial plexus technique. ${ }^{1}$ The ability to administer this block with precision has become possible with the advent of ultrasound, peripheral nerve stimulator, echogenic needles, depth coded needles, non-stimulating and stimulating catheters. Local anaesthetics alone do not provide analgesia for more than 3-4 hours. Prolonging the duration of sensory and motor blockade of regional anaesthetic techniques is often desirable to provide intra operative anesthesia and analgesia in the post operative period without any systemic side effects. Several adjuncts have been studied to potentiate efficacy of brachial plexus block including opioids, midazolam, neostigmine, bicarbonate, hyaluronidase and $\alpha 2$ agonist. ${ }^{2,3}$

Dexamethasone, a derivative of synthetic glucocorticoid, is preferred because of its highly potent anti inflammatory and immunosuppressive effect. It causes skin vasoconstriction on topical application which decreases absorption of local anaesthetic agent and there by prolongs the duration of action. ${ }^{4}$ The effect of dexamethasone is mediated by direct blockade of transmission in nociceptive C- fibres, reducing the release of inflammatory mediators andectopic neuronal discharge, and upregulation of potassium channels. ${ }^{5}$ Perineural glucocorticoid is eventually absorbed and exerts systemic effects and intravenous steroids shown to improve postoperative pain and also decreases postoperative nausea and vomiting. ${ }^{6}$

Ropivacaine, the S-enantiomer of S-1-propyl-2, 6 -pipecoloxylidide is an amino-amide local anesthetic with a chemical structure similar to that of bupivacaine. Numerous comparative studies between ropivacaine and bupivacaine suggested that ropivacaine produced less cardiac and central nervous system toxic effects, less motor block, and a similar duration of action of sensory analgesia. This favorable clinical profile prompted 
many clinicians to switch from bupivacaine to ropivacaine. Present study was done to compare the efficacy of sensory and motor onset of $0.5 \%$ Ropivacaine with dexamethasone $8 \mathrm{mg}$ as adjuvant, in supraclavicular brachial plexus block.

\section{Materials and Methods}

The study was conducted in a randomized double blind manner, in the department of anaesthesiology at Dr. D. Y. Patil Medical College and Hospital .Written informed consent was obtained from all patients willing to be part of the study. After the approval of the institutional ethics committee, the study was conducted on 60 healthy patients of both sex aged between 18- 65 years. ASA grade I and II, undergoing upper extremity surgery and hemodynamically stable were included in the study. Patients with bleeding disorder or patients on anticoagulation therapy, uncooperative, underlying respiratory disease, history of drug allergy, abnormal psychological profile, convulsions and peripheral nerve diseases were excluded from the study. 60 patients were divided into two equal groups of 30 each.

Group RD: Inj. $0.5 \%$ Ropivacaine $28 \mathrm{ml}$ with $2 \mathrm{ml}$ dexamethasone $(8 \mathrm{mg})$ making total volume $-30 \mathrm{ml}$ Group RS: Inj. $0.5 \%$ Ropivacaine $28 \mathrm{ml}$ with $2 \mathrm{ml}$ Normal Saline making total volume $-30 \mathrm{ml}$.

Drug was prepared by an anesthesiologist who was not involved in the administration of anesthesia, patient care and data collection. The drug was given by a double blind method. Every patient was evaluated with a thorough pre-anesthetic checkup including routine preoperative investigations one day prior to surgery. Patients were asked to have 6 to 8 hours fasting before surgery. Pre-operative explanation of the procedure was done to gain confidence of the patient and written informed consent for surgery was taken.

In the operation theatre, intravenous (IV) line was secured with 20G intra cath and IV fluids were started. Routine monitors like pulse oxymetry $\left(\mathrm{SPO}_{2}\right)$, noninvasive blood pressure (NIBP), electrocardiogram (ECG) were attached before performing the procedure. Supraclavicular brachial plexus block was performed under all aseptic precautions in supine position with small bolster under the shoulder and head turned slightly to the opposite side. The arm to be anesthetized was adducted and the hand extended along the side towards the ipsilateral knee as far as possible. We used a nerve stimulator with a 22-G, $5-\mathrm{cm}$ insulated needle for precise localization of the brachial plexus. A skin wheal was raised in the lateral border of middle scalene muscle 1.5-2 cms posterior to the midpoint of clavicle. The subclavian artery was usually be palpated at this site. Nerve locator was used, whose frequency was set at $2 \mathrm{~Hz}$ and intensity of the stimulating current was initially set to deliver $1 \mathrm{~mA}$ for $0.1 \mathrm{~ms}$. The insulated needle was inserted through the skin wheal in a posterior, caudal and medial direction until a distal motor response is elicited. As the nerve was approached, movement of the wrist or fingers elicited was identified and the current was gradually reduced to $0.4 \mathrm{~mA}$. The end point taken was when hand twitches could be elicited at a current of $0.4 \mathrm{~mA}$. Once this was achieved, the test drug in $0.5 \%$ Ropivacaine was given in $5 \mathrm{ml}$ increments, aspirating before each bolus for blood and air, to avoid accidental intravascular injection. Patient was monitored closely after completing the local anaesthetic injection. The sensory level was assessed using a 24- gauge short beveled needle by bilateral loss of pin prick every 1 minute till the fixation of sensory level and attaining a maximum sensory level.

Assessment of sensory block: Onset of sensory block was evaluated by pin prick sensation. Dull sensation on pin prick, which was compared with the other arm, was taken as the time of onset of sensory blockade.

Onset of peak sensory blockade: it was taken from the time of administration of drug upto the time of complete loss of pinprick sensation at the forearm; and also no complaint of pain on manipulation of the fracture.

Assessment of motor block: The motor block was assessed with the help of modified bromage scale.

Onset of motor blockade, was considered from the injection of drug upto the time when patient felt heaviness on abduction of arm, at shoulder or on achieving bromage scale 1 where

0 -Able to raise the extended arm to 90 degree for a full 30 seconds;

1-Able to flex the elbow and move the fingers but unable to raise the extended arm.

2-Unable to flex the elbow but able to move the fingers.

3-Unable to move the arm, elbow or fingers.

Onset of peak motor blockade, was taken from the injection of drug upto the time of achieving bromage scale 2 or 3 . Vital parameters were monitored every 5 mins for the first 15 mins and every 15 minutes till the end of the surgery. Patients were monitored for any adverse effects (cough, chest pain, hoarseness of voice). After surgery patient was shifted to post-operative recovery room and assessment of duration of analgesia was done upto 24 hours using VAS scale. Duration of analgesia was taken from the time of administration of drug to the time of giving first rescue analgesia. 
Post-operative rescue analgesia (with Inj. Diclofenac Sodium 75mg) was given if the patient complains of moderate pain (VAS $>4$ ). The patients were taught to assess the intensity of pain using visual analogue scale (VAS) for post-operative pain assessment. It is a $10 \mathrm{~cm}$ line on a white paper and represents patient's degree of perception of pain. Patient rates the degree of pain by making a mark on the linear scale. Score was measured by taking the distance from 0 to the patient's marked point. The VAS scoring is done as : 0-3 Mild Pain 3-7 Moderate Pain $>7$ Severe Pain

Statistical Analysis: All the Data were checked, filled up in the proforma and were analysed .The unpaired t-test and $\mathrm{z}$ - test were used for comparison between two groups. $\mathrm{P}<0.05$ value was considered significant.

\section{Results}

The Demographic data of both the groups were comparable (Table 1) ( $>00.05)$. Onset of Sensory block was earlier in group $\mathrm{RD}$ as compared with group $\mathrm{R}(\mathrm{p}<0.05)$. There was no significant difference in the onset of motor block in the 2 groups ( $p>0.05)$. Onset of peak sensory block was earlier in RD than $R S(p<0.05)$, however onset of peak motor was not significant enough. Total duration of sensory and motor blockade in group RD was longer than in group $\mathrm{R}(\mathrm{p}<0.001)$. Longer postoperative analgesia was also seen in group $\mathrm{RD}$. $(\mathrm{P}<0.001)$. There was no side effect in either of group and patients in both groups were haemodynamically stable.

Table1: Demographic Data

\begin{tabular}{|c|c|c|c|}
\hline Data & Group Rs & Group Rd & P Value \\
\hline Age (Years) & 37 & 35 & $>0.05$ \\
\hline Sex (M:F) & $18: 12$ & $20: 10$ & $>0.05$ \\
\hline Weight (Kg) & 63 & 62 & $>0.05$ \\
\hline ASA (I:II) & $21: 9$ & $23: 7$ & $>0.05$ \\
\hline Duration of Surgery (Min) & $100 \pm 23$ & $96 \pm 25$ & $>0.05$ \\
\hline
\end{tabular}

$\mathrm{P}$ value $>0.05$ statistically insignificant

Table 2: Comparison of sensory block, motor block and rescue analgesia

\begin{tabular}{|c|c|c|c|}
\hline Parameters & Group Rs & Group Rd & P Value \\
\hline Onset Of Sensory Block (Min) & 11.25 & 9.01 & $<0.05$ \\
\hline Onset Of Motor Block (Min) & 14.07 & 13.07 & $>0.05$ \\
\hline Time Of Peak Sensory Block (Min) & 16.04 & 14.20 & $<0.05 \dagger$ \\
\hline Time Of Peak Motor Block (Min) & 18.43 & 17.36 & $>0.05$ \\
\hline Total Duration Of Sensory Block (Hours) & 6 & 11.05 & $<0.05 \dagger$ \\
\hline Total Duration Of Motor Block (Hours) & 6.25 & 10.05 & $<0.05 \dagger$ \\
\hline Request Of First Rescue Analgesia (Hours) & 7.2 & 13.60 & $<0.05 \dagger$ \\
\hline
\end{tabular}

$\dagger \mathrm{P}$ value $<0.05$ statistically significant

\section{Discussion}

Brachial plexus block is an easy and relatively safe procedure for upper limb surgeries. Ropivacaine provided better operating conditions, but the duration of analgesia is rarely maintained for more than 4-6 h. Addition of steroid to local anesthetics effectively and significantly prolongs the duration of analgesia as well as producing earlier onset of action. ${ }^{7}$

Kumud et al in 2014 studied the efficacy of dexamethasone as an adjuvant to $0.5 \%$ ropivacaine for brachial plexus block and they observed faster onset time of sensory and motor block with dexamethasoneropivacaine combination as compared to ropivacaine with normal saline which is similar with our study. ${ }^{8}$ The early onset of action might be due to synergistic action of dexamethasone with local anesthetics on blockage of nerve fibers. ${ }^{9}$ 
Ahmad et al in 2013 conducted same study and found that duration of effective sensory blockade was prolonged with $0.5 \%$ ropivacaine and dexamethasone combination. ${ }^{4}$ In our study we also found, duration of effective sensory action with ropivacaine and dexamethasone lasted for 11.05 hours $(\mathrm{p}<0.5)$. The total duration of motor blockade lasted for 10.05 hours in group RD and 6.25 hours in group RS $(\mathrm{p}<0.05)$.

Similar results were observed in 2006 by Ali et al where the duration sensory blockade was significantly longer with $0.5 \%$ Ropivacaine and dexamethasone group $(10.17 \pm 1.13 \mathrm{hr})$ as compared to $0.5 \%$ Ropivacaine plain $(6.5 \pm 0.6 \mathrm{hr}) .{ }^{10}$ Similarly, in our study the duration of motor blockade was also longer in dexamethasone group $(8.35 \pm 0.81 \mathrm{hr})$ as compared to control group $(7.42 \pm 0.78 \mathrm{hrs})$. In present study, effective analgesia was significantly longer with addition of dexamethasone to $0.5 \%$ ropivacaine and was 13.60 hours and 7.2 hours with plain $0.5 \%$ ropivacaine ( $\mathrm{P}$ value was <0.05). In 2011 K.C. Cummings concluded that, dexamethasone prolongs analgesia from interescalene nerve blocks using ropivacaine or bupivacaine, with the effect being stronger with ropivacaine. ${ }^{11}$

Shrestha and Maharjan in 2011, showed that $8 \mathrm{mg}$ of dexamethasone when added to a lignocaine and bupivacaine for supraclavicular brachial plexus block had a faster onset of action and longer duration of analgesia without any adverse effects. ${ }^{12}$ In our study, rescue analgesia was given at VAS score $\geq 4$. No significant difference was found in both groups in heart rate, systolic blood pressure, diastolic blood pressure at any time interval during monitoring. No significant intra-operative or post-operative complication like intra arterial or intra vascular placement of drugs, pneumothorax, neurotoxicity, cardiotoxicity, nausea and vomiting were found in either of the two groups.

Figure 1: Comparison of onset of sensory block, motor block

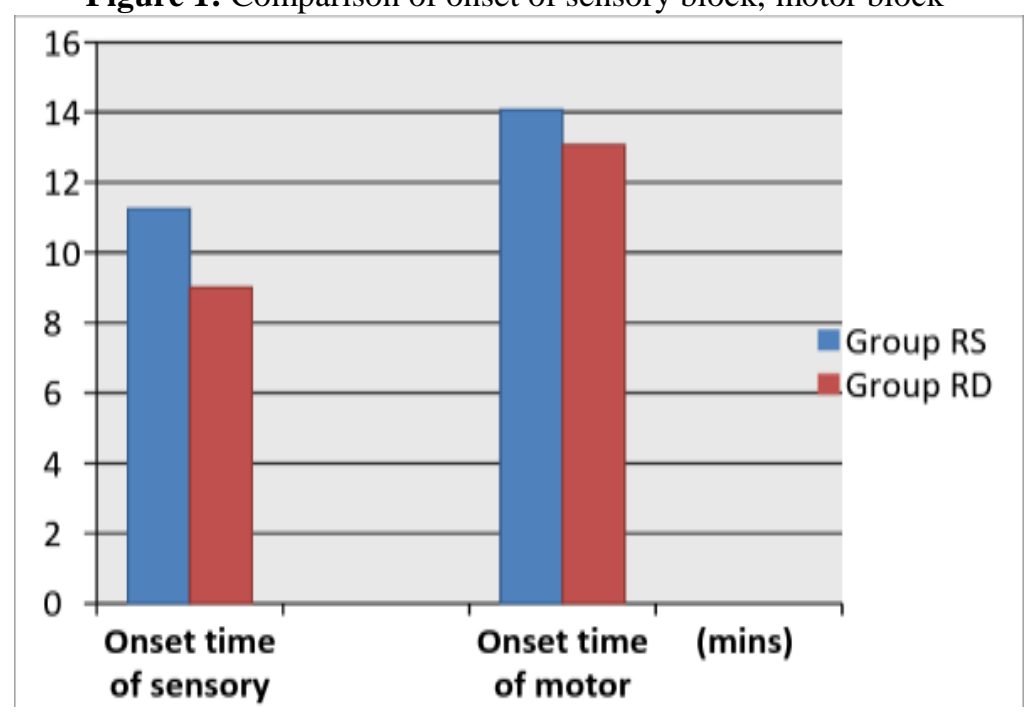

Figure 2: Comparison of onset of peak sensory and peak motor block

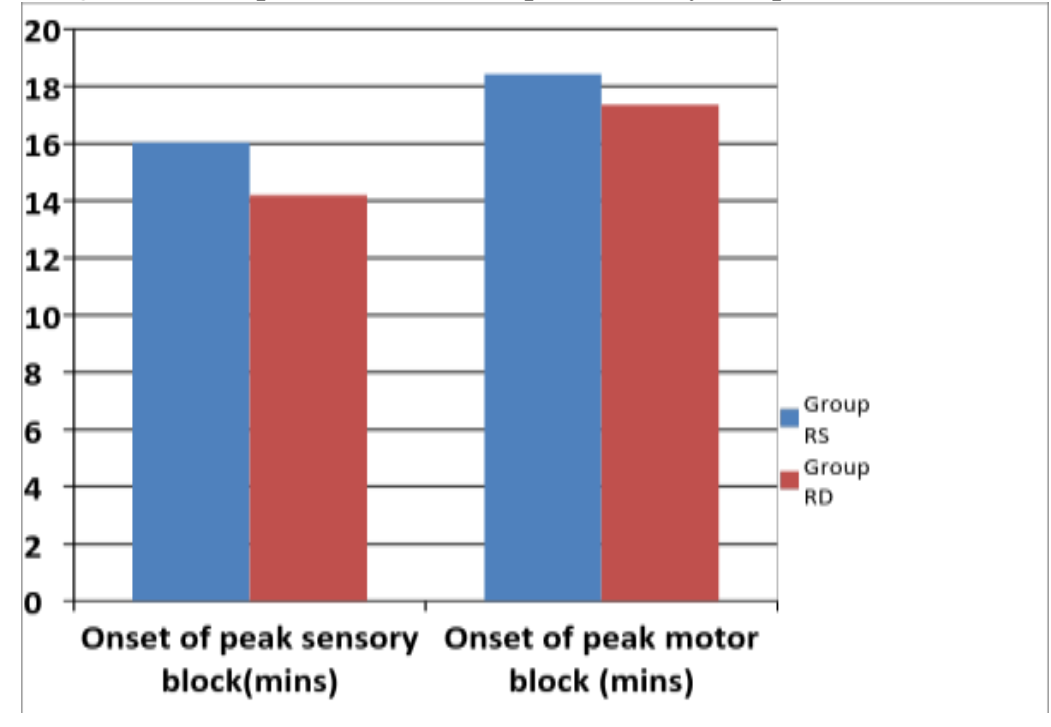


Figure 3: Comparison of duration of sensory, motor block and post op analgesia

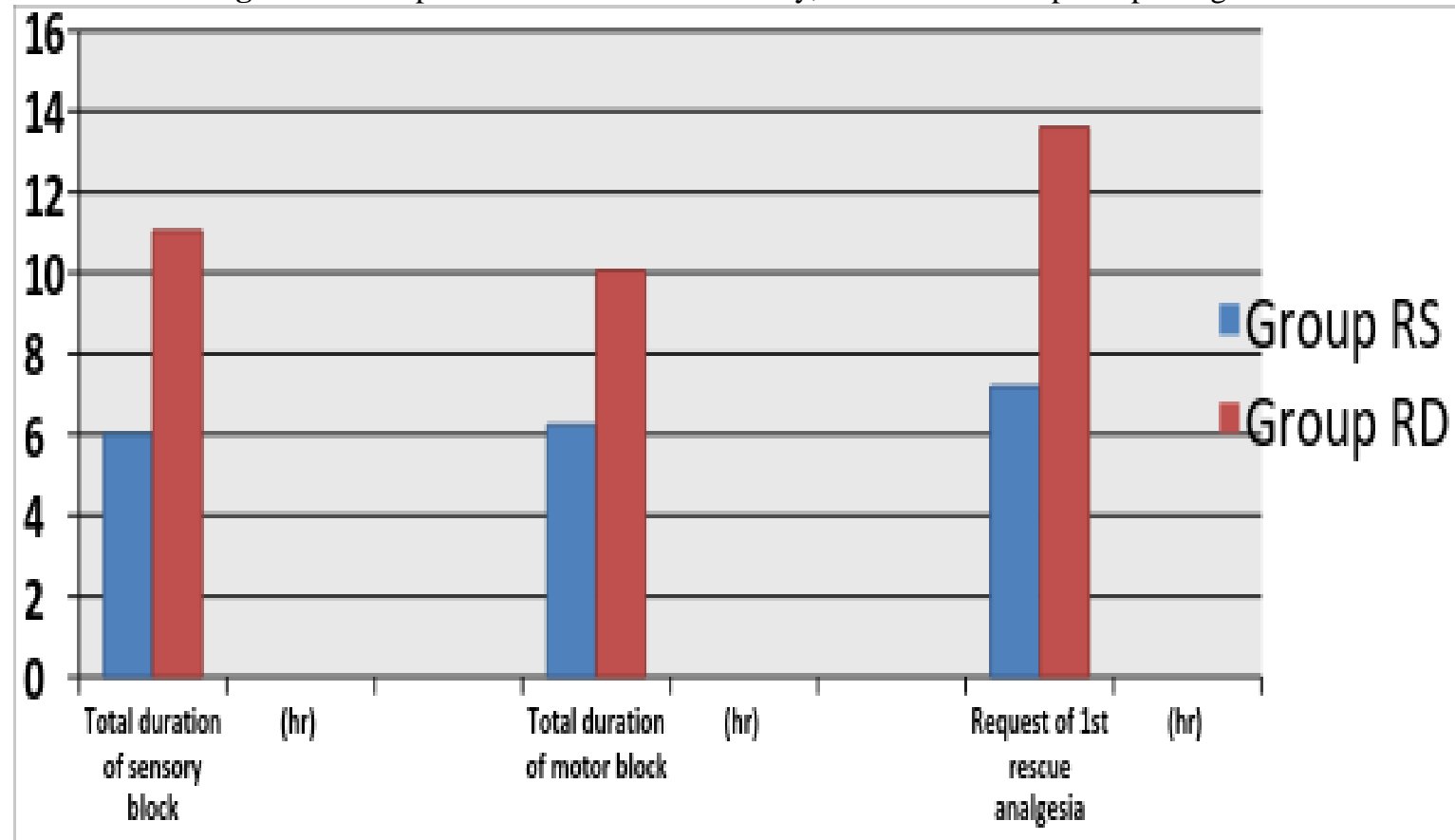

\section{Conclusion}

Dexamethasone $(8 \mathrm{mg}$ ) when added to $0.5 \%$ Ropivacaine fastens the onset of sensory and motor block. It provides longer duration of effective sensory and motor block and prolongs the duration of effective post operative analgesia in patients undergoing surgeries under suprclavicular brachial plexus block.

\section{References}

[1]. Wildsmith JAW, Armitage EN, McClure JH. Principles and Practice of Regional Anaesthesia. Churchill Livingstone 2003; 3: 193 204.

[2]. Fisher L, Gordon M, Wolfie SW, Hotchkiss RN, Pederson WC. Anesthesia for hand surgery.Green's Operative Hand Surgery. Philadelphia: Elsevier/Churchill Livingston 2011; 6: 25-40.

[3]. Raminder l, Anjam T, Baljit S. Brachial Plexus Block. Revisited.Yearbook of Anesthesiology 2015; 4(1): 67-70.

[4]. Feroz Ahmad Dar, Neelofar Jan. Effect of Addition of Dexamethasone to ropivacaine in Supraclavicular brachial plexus block. IOSR 2013; 10 (4): 01-05.

[5]. Choi S, Rodseth R, McCartney CJ. Effects of dexamethasone as a local anaesthetic adjuvant for brachial plexus block: a systematic review and meta-analysis of randomized trials. Br J Anaesth 2014; 112:427-39.

[6]. Ali NS, Patrick MH, Kimberly G, Colleen M, Ashton PF. Electrical nerve stimulators and localization of peripheral nerves. The New York school of regional anesthesia. 2013

[7]. Golwala MP, Swadia VN, Dhimar AA, Sridhar NV. Pain relief by dexamethasone as an adjuvant to local anesthetics in supraclavicular brachial plexus block. J Anaestg Clin Pharmacol 2009; 25:285-8.

[8]. Kumud S. Ganvit, Akshay HM., Isha Singhal, MR. Upadhyay. The efficacy of dexamethasone added as an adjuvant to ropivacaine (0.5\%) for brachial plexus block. Int J Res Med. 2014; 3(1): 71-4.

[9]. Santosh Kumar, UrmilaPalaria, Ajay K. Sinha, D. C. Punera, and VijitaPandey. Comparative evaluation of ropivacaine and ropivacaine with dexamethasone in supraclavicular brachial plexus block for postoperative analgesia. Anesth Essays Res. 2014; 8(2): 202-8.

[10]. Ali M, Mehran R, Fatemeh H, Alipasha M. Dexamethasone added to Lidocaine Prolong Axillary Brachial Plexus Blockade. Anesth Analg 2006; 102: 263-7.

[11]. Cummings KC et al. Effect of Dexamethasone on the duration of interscalene nerve blocks with ropivacaine or bupivacaine. British Journal of Anaesthesia 2011; 107(3): 446-53

[12]. Shrestha BR, Maharjan SK,Tabedar S. Supraclavicular brachial plexus block with and without dexamethasone - A comperative study. Kathmandu University Medical Journal 2003;1:158-60.

\section{Acknowledgement: Nil}

